\title{
A Compreensão de Masculinidade em Discursos de Profissionais de Unidades Básicas de saúde
}

The Understanding of Masculinity in the Speeches of Professionals of Basic Health Units La Comprensión de la Masculinidad en Discursos de Profesionales de Unidades Básicas de Salud

\author{
Lúcia Jamilly Oliveira Morais ${ }^{1}$ \\ Universidade Estadual da Paraíba \\ Pedro de Oliveira Filho \\ Universidade Federal de Campina Grande
}

\begin{abstract}
Resumo
Este artigo objetiva analisar as definições de masculinidade em formulações de profissionais de saúde da Atenção Primária. Este estudo é motivado pela compreensão de que, no âmbito da atenção à saúde dos homens, os profissionais de saúde tem participação fundamental nas ações em saúde destinada ao público masculino. Utilizou-se como abordagem teórico-metodológica a Psicologia Social Discursiva, uma abordagem no contexto da Psicologia Social que privilegia, em termos analíticos, a função do discurso e as estratégias retóricas utilizadas em sua elaboração. A pesquisa, de natureza qualitativa, contemplou 11 entrevistas semiestruturadas com profissionais de oito Unidades Básicas de Saúde da cidade de Campina Grande, PB. Os homens, em seus relatos, teriam diferentes atributos, dentre eles a despreocupação com a saúde, e tais atributos seriam fundamentalmente determinados por fatores socioculturais.

Palavras-chave: masculinidade, saúde pública, profissionais da saúde
\end{abstract}

\begin{abstract}
This article aims to analyze the definitions of masculinity in formulations of health professionals of Primary Care. This study is motivated by the understanding that, in the context of health care for men, health professionals have a fundamental role in health actions for the male population. It was used as a theoretical-methodological approach the Discursive Social Psychology, an approach in the context of Social Psychology that privileges, in analytical terms, the discourse function and the rhetorical strategies used in its elaboration. The research, of qualitative nature, included 11 semi-structured interviews with professionals from eight Basic Health Units of the city from Campina Grande, PB. Men, in their reports, would have different attributes, among them the unconcern with health, and such attributes would be fundamentally determined by sociocultural factors.

Keywords: masculinity, public health, health professionals

Resumen

Este artículo objetiva analizar las definiciones de masculinidad en formulaciones de profesionales de salud de la Atención Primaria. Este estudio está motivado por la comprensión de que, en el ámbito de la atención a la salud de los hombres, los profesionales de salud tienen participación fundamental en las acciones en salud destinada al público masculino. Se utilizó como abordaje teórico-metodológico la Psicología Social Discursiva, un abordaje en el contexto de la Psicología Social que privilegia, en términos analíticos, la función del discurso y las estrategias retóricas utilizadas en su elaboración. La investigación, de naturaleza cualitativa, contempló 11 entrevistas semiestructuradas con profesionales de ocho Unidades Básicas de Salud de la ciudad de Campina Grande, PB. Los hombres, en sus relatos, tendrían diferentes atributos, entre ellos la despreocupación con la salud, y tales atributos serían fundamentalmente determinados por factores socioculturales.

Palabras clave: masculinidade, salud pública, profesionales de la salud
\end{abstract}

\footnotetext{
${ }^{1}$ Endereço de contato: Rua Antônio Joaquim Pequeno, 242, Apartamento 02. Bairro Conjunto dos Professores, Campina Grande, Paraíba, Brasil. E-mail: jamillypsic@gmail.com
} 


\section{Introdução}

Este artigo é um recorte de uma pesquisa mais ampla que aborda a atenção à saúde dos homens na perspectiva de profissionais que trabalham em Unidades Básicas de Saúde. A relação entre homens e saúde vem sendo bastante discutida nos últimos anos, e essa discussão vem dando visibilidade a diversas questões que permeiam esse campo, como as questões de gênero, a atenção à saúde destinada ao público masculino, a paternidade, o acesso dos homens aos serviços de saúde, dentre outros assuntos. Segundo Gomes (2011), nos anos 70 a relação entre homens e saúde era pensada e discutida, sobretudo, pautando-se em questões biológicas e epidemiológicas, e somente a partir dos anos 90 é que as discussões sobre esse tema passaram a considerar outras variáveis, como as questões de gênero e masculinidade, portanto, pensando saúde-doença a partir de uma perspectiva relacional de gênero (Schwarz et al., 2012; Schraiber, Gomes, \& Couto, 2005)

Na esfera da saúde pública brasileira, a saúde do homem recebeu menos atenção se comparada a ênfase tradicionalmente dispensada à saúde da mulher (Couto et al., 2010), uma vez que as políticas de controle populacional e de caráter higienista, que começaram no espaço público e depois direcionaram-se para o espaço privado, foram voltadas, em sua maioria, a outros grupos sociais, como mulheres, idosos e crianças (Carrara, Russo, \& Faro, 2009; Vieira, 2002).

Segundo Vieira (2002), o suposto potencial ameaçador do corpo feminino, no que diz respeito à ordem social e à moral, o tornou alvo das investidas de controle do Estado e da medicina. Desse modo, enquanto as mulheres tiveram seus corpos expropriados pelas ações de saúde higienistas e por estratégias biopolíticas de disciplina e controle reprodutivo, os homens, por sua vez, continuaram a ser vistos como representantes universais.

Nesse contexto, a partir dos anos 70, os movimentos feministas e de gays passaram a lutar pela redução das desigualdades de gênero, buscando a inclusão de outras questões do feminino para além de uma atenção à saúde estritamente materno-infantil, e possibilitando pensar a saúde, de homens e mulheres, a partir de uma perspectiva relacional de gênero (Rohden, 2001; Aquino, 2005; Vieira, 2002; Gomes, Nascimento, \& Araújo, 2007).

Nas décadas seguintes alguns estudos identificaram uma maior mortalidade e uma menor expectativa de vida da população masculina em comparação com a população feminina, e atribuíram essa suposta diferença tanto a fatores biológicos quanto a fatores socioculturais (Figueiredo, 2005; Laurenti, Mello-Jorge, \& Gotlieb, 2005; Carrara et al., 2009; Gomes, 2012; Vieira, Gomes, Borba, \& Costa, 2013).

Medrado, Lyra, Azevedo, Granja, e Vieira (2009) chamam atenção para os altos índices de adoecimento e mortalidade dos homens relativos a "causas externas", tais como o suicídio, a violência, acidentes, etc. Essas causas seriam, em parte, reflexos do modo de ser homem na sociedade brasileira, que ainda está bastante relacionado a práticas de risco, ao poder e à violência, construindo assim uma masculinidade, para a qual "ser homem" seria sinônimo do não exercício de práticas de cuidado de si e dos outros. Para Schraiber et al. (2005), a interface entre violência e masculinidade fica mais nítida se pensada através da perspectiva de gênero, uma vez que o exercício da violência faz parte, por vezes, do processo de socialização e reafirmação da masculinidade hegemônica, podendo, inclusive, trazer consequências desvantajosas para a saúde desse grupo social. Nesse contexto, vale salientar que, ao falarmos 
sobre gênero, não estamos nos restringindo a dicotomia homem e mulher, mas pensando em uma dimensão maior que se pauta sobretudo na diversidade e na desconstrução de uma lógica binária e hierarquizada (Medrado \& Lyra, 2014).

De acordo com Scott (1995), 'gênero' passa a ser compreendido como "construções sociais" sobre os papéis próprios de homens e mulheres dentro de uma realidade social. Nesse sentido, ser homem ou ser mulher consistiria na incorporação dessas construções sociais pelos sujeitos. Scott (1995) conceitua 'gênero' sugerindo as seguintes proposições: "(1) o gênero é um elemento constitutivo de relações sociais baseadas nas diferenças percebidas entre os sexos e (2) o gênero é uma forma primária de dar significado às relações de poder" (p. 86).

Segundo Korin (2001), falar de gênero requer considerar diversos fatores e marcadores sociais (como etnia, classe social, raça, idade, questões socioeconômicas, etc.) que atravessam esta concepção, distanciando-se de uma definição de gênero monolítica e estereotipada, e dando visibilidade a uma pluralidade de modos de ser.

Nesse sentido, Vale de Almeida (1996) ressalta que a compreensão de masculinidade não se reduz aos homens, uma vez que os termos masculinidade e feminilidade são metáforas de poder e de ação disponíveis tanto para homens como para mulheres. Desse modo, é plausível considerar que ao tratarmos sobre a saúde dos homens, ou no caso deste estudo da atenção à saúde dos homens, não referimos, necessariamente, a indivíduos que possuem um corpo com atributos do sexo masculino, mas sim a "sujeitos em exercício de masculinidades" (Schraiber et al., 2005). No contexto da saúde, compreender os homens a partir dessa perspectiva faz com que as ações destinadas a esse público sejam elaboradas de modo mais plural e abrangente, não restringido a um determinado grupo de homens.

De acordo com Gomes (2012), no que diz respeito à atenção à saúde dos homens, e principalmente para que as ações voltadas a esse público tenham êxito, faz-se necessário compreender a existência de uma pluralidade de formas de exercer a masculinidade, não restringindo-se a um único modelo, dito hegemônico. Essas variadas formas de masculinidade são influenciadas por vários fatores, como a raça, classe social, grupo etário, etc. e devem ser considerados pelos serviços e profissionais de saúde ao elaborarem ações voltadas aos homens.

Em 2008, tendo em vista os altos índices de morbimortalidade da população masculina e os resultados de vários estudos que apontavam uma menor frequência dos homens nas Unidades Básicas de Saúde, o Ministério da Saúde criou a Política Nacional de Atenção Integral à Saúde do Homem (PNAISH), na tentativa de promover uma maior presença dos homens nos serviços de saúde (especialmente na Atenção Primária à Saúde), e de incentivar uma maior atenção dos serviços e profissionais de saúde junto as demandas do público masculino (Brasil, 2009).

Essa política, que vem se consolidando ao decorrer dos anos, tem feito parte de muitos estudos, sendo, inclusive, alvo de algumas considerações críticas. Para alguns autores (Medrado et al., 2009; Carrara et al., 2009; Medrado, Lyra, Azevedo, \& Noca, 2010), a PNAISH pauta-se, sobretudo, por uma literatura epidemiológica tradicional sobre "riscos", apresentando uma compreensão clássica do adoecimento e mortalidade dos homens, e deixando as questões de gênero em um segundo plano. Outros autores (Martins \& Malamut, 2013) salientam ainda que a PNAISH foi construída e tem sido implementada em "nome dos homens", mas pouco dá voz a essa categoria no que diz respeito aos processos decisórios da política. 
Nos objetivos da PNAISH, observa-se uma preocupação legítima com os profissionais de saúde que compõem os serviços, uma vez que são eles os responsáveis por executar as ações em saúde junto ao público masculino. Tendo em conta que o modo como os profissionais definem a masculinidade pode influenciar no processo de construção de estratégias de atendimento e acolhimento do público masculino (Vieira et al., 2013), esta pesquisa buscou compreender como os profissionais de saúde de uma cidade média da Paraíba, que trabaIham em Unidades Básicas de Saúde, definem a masculinidade.

\section{Procedimentos metodológicos}

A pesquisa, de natureza qualitativa, foi realizada com profissionais de saúde de Unidades Básicas de Saúde da cidade de Campina Grande, Paraíba. A quantidade de participantes da pesquisa não foi definida a priori, uma vez que buscou-se atingir o maior número de participantes até que o material coletado chegasse ao seu ponto de saturação, ou seja, quando começasse a haver repetição de conteúdos nas entrevistas (Lang, Campos, \& Demartini, 2001). O contato com os profissionais deu-se por conveniência (Cozby, 2003), uma vez que alguns participantes foram indicações de amigos e outros já eram conhecidos de um dos pesquisadores.

A coleta de dados deste estudo foi realizada durante os meses de Outubro e Novembro de 2016, após a anuência formal por parte da Secretaria de Saúde da cidade e a referida aprovação do estudo pelo Comitê de Ética em Pesquisa da Universidade Estadual da Paraíba. Objetivando contemplar os aspectos éticos fundamentais em pesquisa indicados pela Resolução no 466/2012 do Conselho Nacional de Saúde, que define as diretrizes para estudos com seres humanos e normatiza a proteção dos direitos dos envolvidos na pesquisa, as entrevistas com os profissionais de saúde foram realizadas somente após a concordância voluntária dos participantes e mediante a assinatura do Termo de Consentimento Livre e Esclarecido (TCLE) e um Termo de Gravação de Voz.

$\mathrm{Na}$ coleta de dados, foram realizadas 11 entrevistas semiestruturadas com profissionais de 8 Unidades Básicas de Saúde da cidade. A entrevista semiestruturada foi composta por um roteiro básico de perguntas referentes ao tema de pesquisa. Todas as entrevistas foram gravadas em um dispositivo de captura de áudio e depois foram transcritas em arquivo Word, transcrição que procurou ser fiel ao conteúdo e à forma da oralidade. Foi utilizada a expressão "participante $\mathrm{n}$ " para identificar os entrevistados, objetivando manter em sigilo suas identidades. Os seguintes profissionais foram entrevistados: seis profissionais de enfermagem, dois de medicina, uma profissional de serviço social e dois técnicos em enfermagem. Dentre os entrevistados, nove são mulheres e dois são homens. No que diz respeito ao período de atuação profissional, há uma variabilidade de 1 a 30 anos.

Este estudo utilizou como abordagem teórico-metodológica a Psicologia Social Discursiva, uma abordagem construcionista que se utiliza do método de análise de discurso. Este não é um método padronizado, que estabelece procedimentos sequenciais que devem ser seguidos à risca no intuito de obter um resultado final que exprima um conhecimento verdadeiro sobre determinado fenômeno. Na Análise de Discurso, o que se propõe é trabalhar a linguagem em uso, seu papel na vida social, e suas funções, buscando analisar as mais diversas manifestações discursivas (Antaki, Billig, Edwards, \& Potter, 2003; Potter, 1998; Potter \& Wetherell, 1987). 
Após a transcrição das entrevistas, foram realizadas leituras intensas e cuidadosas do material discursivo obtido, uma vez que tal exercício permite uma maior aproximação dos analistas em relação ao conteúdo. No método da Análise de Discurso a codificação consiste em uma análise preliminar que visa organizar o material bruto em categorias, possibilitando uma análise mais minuciosa, uma análise atenta aos detalhes do discurso (Potter \& Wetherell, 1987; Gill, 2003). A análise do material obtido objetiva identificar o modo de construção e as funções do discurso, buscando evidenciar o modo como os argumentos discursivos são arranjados retoricamente para construir versões de ações, do eu e das estruturas sociais (Potter, 1998; Wetherell \& Potter, 1992).

\section{Resultados e Discussão}

\section{Definindo a Masculinidade}

Bento (2006) salienta que questões do tipo "O que é ser homem" ou "O que é ser muIher" possibilitam a expressão e a construção de idealizações e pressuposições acerca dos gêneros, permitindo a elaboração de um conjunto de verdades e normas que podem, inclusive, provocar uma hierarquização entre os gêneros.

Os modos de compreender a masculinidade se ampliaram nos últimos anos, concomitantemente às discussões pautadas numa perspectiva relacional entre os gêneros. A ideia de uma única masculinidade, a hegemônica, deu lugar ao que Korin (2001) denomina de uma pluralidade dos modos de ser que procura distanciar-se de uma definição de gênero estereotipada, estática e binária.

Nos discursos analisados os participantes apresentaram diferentes definições de masculinidade e as fundamentaram em pressupostos biologizantes, socioculturais e individualizantes. Os biologizantes pautam-se, principalmente, em elementos anatômicos e fisiológicos. Os pressupostos socioculturais versam, sobretudo, sobre um conjunto de idealizações e de papéis socioculturais que seriam próprios a cada gênero. Os pressupostos individualizantes colocam em primeiro plano a autonomia do sujeito no processo de definição de sua identidade de gênero.

\section{Definições biologizantes}

Um único participante apresentou uma definição de masculinidade fundamentada unicamente na biologia, como se pode ver abaixo.

Entrevistadora: De que modo você compreende o que é ser homem? Participante 6: Eu entendo do ponto de vista biológico, aquele que nasce com... os cromossomos XY. (Médico, 38 anos)

O participante 6 afirma que homem é "aquele que nasce com...os cromossomos $X Y$ ". No campo de estudo da Biologia, a determinação do sexo dos seres humanos dá-se pelo sistema $X Y$. Nesse sistema as fêmeas são os seres que possuem dois cromossomos sexuais do mesmo tipo $(X X)$ e os machos são os seres que possuem dois cromossomos sexuais diferentes (XY).

O modo como ele define a masculinidade contém em si uma afirmação tácita, não dita, afirmação que emerge como consequência daquilo que ele diz. O participante não afirma, 
como é comum em argumentos biologizantes mais elaborados, que os homens (e as muIheres) possuem determinadas qualidades morais e psicológicas que são próprias deles e que são determinadas pela biologia. Na verdade, ele não menciona quaisquer qualidades morais ou psicológicas que seriam próprias dos homens. O que ele diz é que compreende os homens (e por consequência as mulheres) partindo "do ponto de vista biológico", o que é uma outra maneira de dizer que os compreende como seres essencialmente biológicos. Essa é uma maneira tácita de dizer que tudo o que supostamente define os homens (e as mulheres), em termos morais e psicológicos, pode ser explicado por sua natureza biológica. Sua definição é muito curta e exclui todos os outros fatores que são recorrentemente mobilizados, por diferentes atores acadêmicos e sociais, na tentativa de compreender o modo (ou os modos) de ser masculino: a cultura, a sociedade, a história.

\section{Definições Socioculturais}

Os participantes mencionaram reiteradamente atributos supostamente masculinos (atributos psicológicos, morais, sociais) e mobilizaram fatores socioculturais para explicar a existência desses atributos. Algumas vezes, essas qualidades morais, psicológicas e sociais se apresentavam misturadas em uma mesma formulação com atributos puramente biológicos, que faziam referência ao corpo, ao fenótipo (embora não sejam biologizantes).

Entrevistadora: Unrrum. Certo. É... de que modo você compreende o que é ser homem? Participante 9: [pausa] O que é ser homem? É ser... um ser em si [pausa breve] como... com todas as suas complexos [sic], todas a suas dimensões, é... lutando por uma sobrevida tanto... eu num, eu num vejo o, o homem como homem em si, eu vejo o homem como ser humano. Como qualquer, com suas complexidades, com... com suas predisposições às doenças, né? Com, com os cuidados necessários que ele tem a ser. $E$ dentro de um, de um contexto social, dependendo da cultura em que ele está inserido, que ele procure a... a... de uma certa forma, ser feliz dentro da sua estrutura de vida. (Enfermeira, 50 anos)

Participante 10 - Questão de gênero, né? É... ser homem ainda está muito ligado à questão de ser o provedor da família, né? De ser o mais vulnerável, porque justamente não se cuida, né? E... e... A gente lembra muito da questão do mundo do trabalho também, né? E que por essas razões e outras eles não... não são muito assíduos no acompanhamento de saúde. (Assistente social, 39 anos)

Participante 2: É... [pausa breve] Rapaz... [risos] Assim, eu acho que ser homem vai além de ser homem propriamente no gênero, de nascer masculino, mas vai essa questão de caráter, da personalidade, acho que ser homem, pra mim, é ter responsabilidade, é constituir uma família, é se cuidar também, porque homem tem essa história de que não se cuida, né, de que não adoece e tem aquela estigma de ser o fortão, então acho que ser homem vai além dessa... disso que a sociedade quer passar pra gente. (Enfermeira, 24 anos)

Participante 4: Mulher, dependendo... é... [pausa] dependendo da pessoa que esteja à minha frente é que eu vou direcionar meu olhar. [pausa] Porque [pausa] é... [pausa] ele 
é homem porque ele... [pausa] ele tem órgãos sexuais que relaciona a ser homem. Mas dependendo da história dele, a necessidade dele não é eu vê-lo apenas como a pessoa do sexo masculino, eu tenho que direcionar um outro olhar. Cuidar da saúde dele, mas sem [reproduz uma fala] "é homem, é homem, é homem". Ele pode tá precisando de um olhar um pouco diferenciado, então [pausa] o que é ser homem? É uma pessoa que nasce do sexo masculino [pausa] e que, com isso, tem necessidades pra ser cuidado relacionado a isso, que é da natureza do corpo do homem, [pausa] mas também tem questões [pausa] que vai além da questão do corpo, [pausa] biológico. Tem questões psicossociais também, relacionadas a essa questão de ser homem. Até mesmo da responsabilidade que eles tem de assumir a questão da sobrevivência da família. Também isso tá relacionado. Então ser homem é isso: [pausa] é uma pessoa que nasce do sexo masculino, que tem um corpo de homem, que deve ser cuidado dentro dessa... da sua necessidade, mas também tem que ser vista com um olhar mais aberto. (Enfermeira, 43 anos)

Participante 3: [pausa] O ser homem... a sociedade da gente, é... [pausa breve] e eu também, compreendo que é a responsabilidade. Como a gente trabalha muito em área... mais de baixo... de baixo... grau de escolaridade, de mais baixo de nível social , a maioria dos homens, 90\%, eles ainda têm a responsabilidade de cuidar da família, de trabalhar, de manter... menos se cuidar. Eles não têm tempo de vim ao posto, nem querem também. Eles não têm essa cultura de...se tratar. É mais a responsabilidade. $E$ coisa deles. (Enfermeira, 29 anos)

Diferentemente da formulação do participante 6 , na qual não se afirma explicitamente que determinados atributos morais, psicológicos ou mesmo sociais seriam próprios dos homens, nas formulações supracitadas vários atributos morais, psicológicos e sociais são apresentados como próprios dos homens. O homem é "provedor da família", é aquele que assume a "sobrevivência da família", que tem a responsabilidade de cuidar da família, "não se cuida", nem é assíduo no "acompanhamento de saúde", por isso é mais "vulnerável". O homem tem "o estigma de ser fortão", não tem tempo de ir ao "posto", mas se tivesse não iria porque não quer ir.

Em todas essas falas um grande fator sociocultural aparece, implícita ou explicitamente, como princípio explicativo para todos esses atributos. Esse princípio explicativo é nomeado de diferentes maneiras: "contexto social", "a questão de gênero", a "cultura", "aquilo que a sociedade quer passar para a gente". Em pelo menos uma dessas falas, a da participante 10, um fator de natureza socioeconômica emerge como explicação para o fato de homem não se cuidar: a "questão do mundo do trabalho". Mas no contexto de sua fala esse fator parece ser dependente do que ela denomina de "questão de gênero". Nessa fala o homem, em razão da "questão de gênero", ainda "está muito ligado à questão de ser o provedor da família", por isso é mais preso ao "mundo do trabalho" e não tem tempo de cuidar da saúde. Essas formulações indicam, inequivocamente, o contato dessas profissionais com modelos explicativos que se distanciam do velho naturalismo biológico.

Em uma dessas formulações, a da participante 2, há uma clara dicotomia entre aquilo que o homem é em virtude dos condicionamentos sociais do presente ("fortão", descuidado 
com a saúde) e aquilo que ele poderia se tornar por meio de uma mudança de valores (uma pessoa com "responsabilidade", que constitui "uma família", que cuida do próprio corpo). Quando ela afirma que "ser homem vai além dessa... disso que a sociedade quer passar pra gente", ela não está contrapondo uma espécie de identidade inata e autêntica àquela que é construída socialmente. Ela está contrapondo o homem construído pela sociedade atual com o homem que poderia ser construído se a sociedade fosse outra.

Uma dessas participantes, a participante 9, não menciona atributos masculinos, mas em sua fala o que quer que o homem se torne será uma consequência do "contexto social", "da cultura em que ele está inserido". Há todo um cuidado em sua fala no sentido de evitar apresentar os homens como uma categoria de pessoas com características distintivas, assim ela não vê o homem "como homem em si", ela o vê "como ser humano". Trata-se de uma outra maneira de dizer que a identidade humana, comum a homens e mulheres, é mais importante ou mais fundamental do que a identidade de gênero. É interessante comparar essa estratégia de diluir duas categorias dicotômicas (homens e mulheres) em uma categoria mais ampla (o ser humano) com a mesma estratégia sendo usada com categorias de outra natureza. Em um estudo realizado com brancos da Nova Zelândia (Wetherell e Potter, 1992), em que eles falavam de sua relação com os Maoris, muito frequentemente se definia a tolerância racial (ou a ausência de preconceito racial) como a capacidade de entender que os indivíduos desses dois grupos (Maoris e brancos) são essencialmente membros da espécie humana. No Brasil, pesquisa realizada por Oliveira Filho (2009) identificou, na fala de brancos paulistas, o uso da categoria "mestiços" para negar a existência das categorias "negros" e "brancos" no Brasil.

Trata-se de uma estratégia, própria de um certo humanismo (que alguns considerariam ingênuo), que parece pressupor que o conflito entre categorias sociais pode ser eliminado por meio da diluição dessas categorias numa categoria mais ampla (supraordenada), a identidade humana. Que parece pressupor que a simples afirmação de diferenças entre duas categorias é, por si só, uma formulação essencialista.

As outras participantes que afirmam diferenças não podem ser definidas como essencialistas simplesmente por isso. Na verdade, a atenção às diferenças é fundamental para profissionais que trabalham em políticas públicas. Um técnico de uma instituição que combate à exploração sexual de adolescentes seria menos eficaz se ele não estivesse atento para as diferenças entre a exploração de adolescentes do sexo feminino e exploração de adolescentes do sexo masculino. Da mesma forma, as políticas públicas de combate à pobreza seriam menos eficazes se não estivessem atentas para as diferenças entre famílias negras pobres e famílias brancas pobres (essas últimas não sofrem os efeitos do racismo). É essa atenção às diferenças que é ressaltada na intervenção da participante 4. Quando ela afirma que o cuidado em saúde direcionado aos homens deve levar em "a natureza do corpo do homem" está afirmando o óbvio. Corpos de homens e mulheres têm muita coisa em comum, mas têm muitas diferenças que devem ser levadas em conta por profissionais de saúde se querem cuidar de maneira eficaz da saúde de homens e mulheres, mas ela não está atenta somente às diferenças corporais. Como ela mesma diz, "tem questões" que se situam "além da questão do corpo": questões psicossociais" para as quais o profissional de saúde deve dar atenção se quiser cuidar de fato dos homens. 
Vimos que não faz sentido sugerir que essas profissionais reproduzem um discurso essencialista simplesmente porque afirmam características nos homens que os diferenciariam das mulheres. No entanto, o predomínio de modelos explicativos de natureza sociológica ou antropológica em suas explicações não as vacina contra formulações essencialistas. Podemos ser profundamente essencialistas usando modelos explicativos de natureza sociológica ou antropológica. Como afirmam Wetherell e Potter (1992), olhar simplesmente para o conteúdo de um discurso sem considerar a sua linha argumentativa não nos diz muito sobre a sua natureza. Nas falas acima, não obstante os modelos explicativos de natureza sociocultural, há momentos em que as descrições dos atributos masculinos assumem um tom marcadamente essencialista, como nos momentos em que mencionam a suposta falta de cuidado do homem com sua saúde: "porque justamente não se cuida"; "eles não têm essa cultura de... se tratar".

Não há nada de problemático com a afirmação segundo a qual os homens cuidam menos de sua saúde quando comparados com as mulheres. Há evidências empíricas que sustentam essa afirmação. Ela somente se torna essencialista quando é apresentada como uma característica (não importa se de origem social ou biológica) que se faz presente em todos os homens ou na maioria deles. Quando não se considera as variações nessa característica em homens de diferentes classes sociais. Quando se desconsidera que muitas mulheres, de diferentes classes sociais, cuidam muito pouco de sua saúde quando comparadas com outras mulheres e com homens. Enfim, quando se considera que homens sem esse atributo (ser descuidado com saúde) não são verdadeiramente homens ou são exceções raríssimas que contrariam a regra geral.

Em uma dessas falas, a da participante 3, observa-se a utilização do recurso retórico que Potter (1998) denomina de "quantificação", quando ela apresenta um dado numérico/estatístico no trecho "a maioria dos homens, 90\%, eles ainda têm a responsabilidade de cuidar da família, de trabalhar, de manter... menos se cuidar". O uso desse recurso retórico implica em uma suposta objetividade e veracidade dos dados apresentados, na expectativa de precisar, em números, que a maior parte dos membros de um grupo social ( $90 \%$ dos homens) tem a "responsabilidade de cuidar da família", de trabalhar, etc., e por isso não cuidam da saúde, reiterando a ideia que os que fogem desse padrão não são verdadeiramente homens ou são exceções raríssimas que contrariam a regra geral.

\section{Definições Individualizantes}

Algumas formulações apresentaram outra perspectiva, colocaram em primeiro plano a autonomia do sujeito no processo de definição de sua identidade de gênero. Destacam-se os relatos de duas participantes, uma médica e outra enfermeira, que construíram suas percepções de masculinidade pautando-se, sobretudo, na ideia de identidade de gênero. Vejamos:

Entrevistadora: Certo... De que modo você compreende o que é ser homem?

Participante 11: [Desconforto ao iniciar] Bom, ai é bem difícil da gente responder, principalmente hoje em dia, que tanto se discute questão de gênero, sexualidade e de tudo, né? [pausa] De um modo geral, tem a parte biológica, né? Do nascer geneticamente homem; tem a parte fenotípica, né? Dele se apresentar homem, de... [pausa] do gêne- 
ro masculino, do se sentir homem, e da questão de sexualidade, que aí já é outra coisa mais diferente, né? [pausa- interrupção externa]. Mas de um modo geral ser homem é... [pausa] seria o se sentir, né? O que a pessoa entende por ela mesma. Se ela se acha um homem, se sente do sexo masculino, nada a ver com questões de...não gosto de citar quando pergunta disso, de questão de machismo, de papel na sociedade, nem de nada disso. Acho que é o que o indivíduo entende por ele mesmo ser homem. (Médica, 26 anos)

Entrevistadora: Unrrum... [pausa breve]. É... De que modo você compreende o que é ser homem? Participante 1: [pausa] Ser homem é você se assumir do sexo masculino. Entrevistadora: Unrrum. Participante 1: [pausa breve] Porque... [pausa breve] você pode nascer do sexo masculino e não se assumir como homem. (Enfermeira, 35 anos)

A participante 11 constrói uma percepção de masculinidade pautada em duas instâncias. A primeira refere-se ao homem a partir de uma perspectiva biológica e genética, em que ser homem pode ser entendido como aquele que possui um fenótipo que o insere nesta categoria. A segunda diz respeito a autonomia do sujeito no que diz respeito à definição de sua identidade de gênero. Para ela, sentir-se homem está para além das características biológicas, sendo mais propriamente uma questão de identificar-se como homem, como expressa na seguinte passagem: "Mas de um modo geral ser homem é... [pausa] seria o se sentir, né? o que a pessoa entende por ela mesma". Nesse tipo de compreensão os elementos corporais não determinam o gênero dos sujeitos.

Como forma de endossar e ratificar sua percepção de masculinidade, a participante 11 critica as construções que utilizam elementos como o machismo, e o papel do homem na sociedade para caracterizar e/ou definir o que é "ser homem". Ao exemplificar essas outras formas de compreensão de masculinidade, a participante, implicitamente, se apresenta como alguém que, apesar de saber da existência destas outras formas, as recusa em defesa da autonomia do indivíduo na definição de sua identidade de gênero.

Observa-se que nessa compreensão de masculinidade a participante posiciona o sujeito como autônomo frente a sua identidade de gênero, sendo ele o responsável por designar o que o identifica ou não como homem: "Acho que é o que o indivíduo entende por ele mesmo ser homem".

Da mesma forma, a participante 1 também elabora sua compreensão de masculinidade baseada na ideia de autonomia individual, que diz respeito ao modo como os sujeitos individuais se reconhecem no mundo e como cada um se identifica e afirma seu gênero. Para a participante 1, 'ser homem' diz respeito à identidade, trata-se de assumir uma posição de gênero, independente das características biológicas que constituem o corpo do sujeito. A compreensão de masculinidade elaborada por esta participante permite-nos pensar acerca das possibilidades de apresentar-se homem em uma sociedade, como por exemplo o homem transexual. Homem transexual, a saber, é aquele que nasceu com características corporais referentes ao sexo feminino, mas identifica-se como homem, e, portanto, pode, inclusive, realizar alterações corporais para obter uma equivalência estética que Ihe satisfaça e que esteja em consonância com sua identidade de gênero. Em conformidade com as percepções de masculinidade das participantes 11 e 1, Jesus (2012) assinala que o homem transexual é o sujeito que pleiteia um reconhecimento legal e social enquanto homem. 
A construção discursiva da participante 1 também posiciona o sujeito como autônomo frente à sua identidade de gênero, quando expressa que "ser homem é você se assumir do sexo masculino", criticando, implicitamente, a normatização do gênero baseada no sexo biológico.

Os discursos apresentados nesta categoria de análise diferenciam-se dos vistos anteriormente, uma vez que colocam em primeiro plano o sujeito individual, construindo-o como ativo e autônomo em relação à construção de sua identidade de gênero.

\section{Considerações Finais}

A análise dos discursos dos participantes deste estudo identificou diferentes formas de definir a masculinidade. Um dos participantes mobilizou fatores biologizantes, utilizando o sistema cromossômico XY para elaborar sua definição de masculinidade. Esta definição pode ser considerada uma construção essencialmente biológica, uma vez que o participante não menciona quaisquer outros fatores em sua argumentação.

Outros participantes, por sua vez, mencionaram atributos supostamente masculinos (atributos psicológicos, morais, sociais) e mobilizaram fatores socioculturais para explicar a existência desses atributos. Esses participantes descreveram o homem como "provedor da família", como aquele que assume a "sobrevivência da família", que tem a responsabilidade de cuidar da família, que "não se cuida", que não tem tempo de ir ao "posto", etc. A existência desses atributos seria uma decorrência de fatores socioculturais.

Há que se ressaltar que, não poucas vezes, acentuar ou exagerar a presença de determinado traço psicológico ou moral em um grupo social pode fazer parte de uma estratégia, não necessariamente consciente, de desresponsabilização de um grupo. No caso específico desta pesquisa, apresentar os homens como essencialmente despreocupados com a própria saúde é uma maneira bastante eficaz de colocar no esquecimento a parte de responsabilidade que cabe às instituições públicas de saúde pela baixa frequência dos homens nessas instituições.

Alguns participantes ainda mencionaram a autonomia dos sujeitos individuais no processo de definição de si mesmos, relativizando a influência da cultura, da sociedade e da biologia na definição da identidade masculina.

Os resultados discutidos mostram a ausência de um significado unívoco para o que se entende por masculinidade. Observa-se que os participantes mobilizaram variados fatores para elaborar um conceito de masculinidade, utilizando diferentes repertórios. É interessante destacar que participantes de uma mesma categoria profissional construíram concepções de masculinidade distintas, como os participantes 6 e 11, ambos profissionais da medicina, mas que mobilizaram fatores diferentes em suas conceituações.

As definições construídas por esses participantes podem, ainda que de forma não consciente, orientar o modo como esses profissionais direcionam as ações em saúde ao público masculino. Se faz necessário, portanto, a realização de mais estudos sobre a atenção que vem sendo destinada ao público masculino, e uma atenção especial aos variados discursos que circulam nos contextos de saúde. 


\section{Referências}

Antaki, C., Billig, M., Edwards, D., \& Potter, J. (2003). Discourse analysis means doing analysis: A critique of six analytic shortcomings. Disponível em http://extra.shu.ac.uk/daol/articles/ open/2002/002/antaki2002002-paper.html

Aquino, E. M. L. (2005). Saúde do homem: Uma nova etapa da medicalização da sexualidade? Ciência \& Saúde Coletiva, 10(1), 19-22.

Bento, B. (2006). A reinvenção do corpo: Sexualidade e gênero na experiência transexual. Rio de Janeiro: Garamond.

Brasil (2009). Ministério da Saúde. Política Nacional de Atenção Integral à Saúde do Homem: Princípios e diretrizes. Brasília. Disponível em http://bvsms.saude.gov.br/bvs/publicacoes/ politica_nacional_atencao_homem.pdf

Carrara, S., Russo, J. A., \& Faro, L. (2009). A política de atenção à saúde do homem no Brasil: Os paradoxos da medicalização do corpo masculino. Physis - Revista de Saúde Coletiva, 19(3), 659-678.

Couto, M. T., Pinheiro T. F., Valença, O., Machin, R., Silva, G. S. N., Gomes, R., Schraiber, L. B., \& Figueiredo, W. S. (2010). O homem na atenção primária à saúde: Discutindo (in) visibilidade a partir da perspectiva de gênero. Interface - Comunicação, Saúde, Educação, 14(33), 257-270.

Cozby, P. C. (2003). Métodos de pesquisa em Ciências do Comportamento (P. I. C. Gomide \& E. Otta, Trad.). São Paulo: Atlas.

Figueiredo, W. (2005). Assistência à saúde dos homens: Um desafio para os serviços de atenção primária. Ciência \& Saúde Coletiva, 10(1), 105-109.

Gill, R. (2003). Análise de discurso. In M. W. Bauer, \& G. Gaskell (Orgs.). Pesquisa qualitativa com texto: Imagem e som (pp. 244-269). Petrópolis, RJ: Vozes.

Gomes, R. (2011). Apresentação. In R. Gomes (Org.). Saúde do homem em debate (pp. 1117). Rio de Janeiro: Fiocruz.

Gomes, R. (2012). Sexualidade masculina, gênero e saúde. Rio de Janeiro: Fiocruz.

Gomes, R., Nascimento, E. F., \& Araújo, F. C. (2007). Por que os homens buscam menos os serviços de saúde do que as mulheres? As explicações de homens com baixa escolaridade e homens com ensino superior. Cadernos de Saúde Pública, 23(3), 565-574.

Jesus, J. G. (2012). Orientações sobre a população transgênero: Conceitos e termos. Brasília: Autor.

Korin, D. (2001). Novas perspectivas de gênero em saúde. Adolescência Latinoamericana, 2(2), 67-79.

Lang, A. B. S. G., Campos, M. C. S. S., \& Dermatini, Z. B. S. (2001). História oral e pesquisa sociológica: A experiência do CERU. São Paulo: Humanitas.

Laurenti, R., Mello-Jorge, M. H. P., \& Gotlieb, S. L. D. (2005). Perfil epidemiológico da morbimortalidade masculina. Ciência \& Saúde Coletiva, 10(1), 35-46. Disponível em http://www.scielo.br/pdf/csc/v10n1/a04v10n1.pdf

Martins, A. M., \& Malamut, B. S. (2013). Análise do discurso da Política Nacional de Atenção Integral à Saúde do Homem. Saúde e Sociedade, 22(2), 429-440.

Medrado, B., Lyra, J., Azevedo, M., Granja, E., \& Vieira, S. (2009). Princípios, diretrizes e recomendações para uma atenção integral aos homens na saúde. Recife: Instituto PAPAI. 
Medrado, B., Lyra, J., Azevedo, M., \& Noca, J. (2010). Reflexões irônicas sobre gestão pública dos homens na saúde: Entre a disciplina e a positividade do risco. In B. Medrado, J. Lyra, M. Azevedo, \& J. Brasilino (Orgs.), Homens e masculinidades: Práticas de intimidade e políticas públicas (1a ed., Cap. 3, pp. 53-77). Recife, PE: Instituto PAPAI.

Medrado, B., \& Lyra, J. (2014). Princípios ou simplesmente pontos de partida fundamentais para uma leitura feminista de gênero sobre os homens e as masculinidades. In E. Blay (Org.). Feminismos e masculinidades: Novos caminhos para enfrentar a violência contra a mulher (Vol. 1, pp. 55-74). São Paulo: Cultura Acadêmica.

Oliveira Filho, P. (2009) A mobilização do discurso da democracia racial no combate às cotas para afrodescendentes. Estudos de Psicologia, 26(4), 429-436.

Potter, J., \& Wetherell, M. (1987). Discourse and social psychology: Beyond attitudes and behaviour. London, Sage.

Potter, J. (1998). La representación de la realidade: Discurso, retórica y construcción social. Barcelona: Paidós.

Rohden, F. (2001). A questão da diferença entre os sexos: Redefinições no século XIX. In F. Rohden (2001). Uma ciência da diferença: Sexo e gênero na medicina da mulher (Capítulo 1, pp. 29-49). Rio de Janeiro: Fiocruz.

Schraiber, L. B., Gomes, R., \& Couto, M. T. (2005). Homens e saúde na pauta da Saúde Coletiva. Ciência e Saúde Coletiva, 10(1), 7-17.

Scott, J. (1995). Gênero: Uma categoria útil de análise histórica. Revista Educação e Realidade, 20(2), 71-99.

Schwarz, E., Gomes, R., Couto, M. T., Moura, E. C., Carvalho, S. A, \& Silva, S. F. C. (2012). Política de saúde do homem. Revista Saúde Pública, 46(Supl.), 108-116.

Vale de Almeida, M. (1996). Género, masculinidade e poder - Revendo um caso do sul de Portugal. Anuário Antropológico, 95, 161-190.

Vieira, K. L. D., Gomes, V. L. O., Borba, M. R., \& Costa, C. F. S. (2013). Atendimento da população masculina em Unidade Básica Saúde da Família: Motivos para a (não) procura. Escola Anna Nery, 17(1), 120-127. Disponível em http://www.scielo.br/pdf/ean/v17n1/17.pdf

Vieira, E. M. (2002). A medicalização do corpo feminino. Rio de Janeiro: Fiocruz.

Wetherell, M., \& Potter, J. (1992). Mapping the language of racism: Discourse and the legitimation of exploitation. London: Harvester Wheat Sheaf.

Recebido: 27/10/2017

Última revisão: 15/03/2018

Aceite final: 11/04/2018

Sobre os autores:

Lúcia Jamilly Oliveira Morais - Mestranda em Psicologia da Saúde pela Universidade Estadual da Paraíba. E-mail: jamillypsic@gmail.com

Pedro de Oliveira Filho - Doutorado em Psicologia Social pela Pontifícia Universidade Católica de São Paulo. Mestrado em Psicologia Social pela Universidade Federal da Paraíba. Graduado em Psicologia pela Universidade Estadual da Paraíba. Professor associado I do Curso de Psicologia na Universidade Federal de Campina Grande, PB. E-mail: deoliveirafilhopedro@gmail.com 
